\title{
Power Factor Correction of AC to DC Converter Using Voltage Pulse Width Modulation (P.W.M) Techniques
}

\author{
Ibekwe Basil Esom*, Ezekiel Nnamere Aneke
}

Department of Electrical and Electronic Engineering, Enugu State University of Science and Technology (ESUT), Enugu, Nigeria

DOI: $\underline{10.36347 / \text { sjet.2020.v08i09.001 }}$

| Received: 06.09.2020 | Accepted: 15.09.2020 | Published: 24.09.2020

*Corresponding author: Ibekwe Basil Esom

Abstract

Original Research Article

Power factor correction is a way of counteracting the undesirable effects of electric load that create power factor less than unity. The word "converter" in wider perspectives include all the devices that convert electrical energy from one form to another, e.g. inverters, rectifiers or power pack. The term can also denote frequency converter and/or circuit that beat signals together to form a new signal frequency. Pulse Width Modulation (P.W.M) is a method of varying the mark-to-space ratio of the output voltage waveform during a cycle so as to minimize the magnitude of harmonics in the output. Modulation may be done by using transistors as switches instead of thyristors because transistors have much higher switching frequencies, thus, leading to improve and more efficient operation of the thyristors with switching time of about 1 to $2 \mu$ seconds. In this paper, a single-phase and three-phase bridge rectifier circuits' power factors were modeled and simulated in MATLAB. The resulting voltage wave forms displayed in Figures 4 and 5 respectively showed that P.W.M method is a premier compared with other methods and is also better at low output voltage demand. Again, by using several pulses in each half cycle of the output voltage, it can reduce harmonic contents at low output voltages. In P.W.M, control is made independent of alpha $(\alpha)$, the firing angle of thyristor, and as such all the switching loss problems and electromagnetic interference (EMI) noise associated with switches/switching are totally eliminated here.

Keywords: Converters, harmonic contents, power factor correction, P.W.M method, single and three-phase bridge rectifier circuits, thyristors, transistors, noise and electromagnetic interference (EMI).

Copyright @ 2020: This is an open-access article distributed under the terms of the Creative Commons Attribution license which permits unrestricted use, distribution, and reproduction in any medium for non-commercial use (NonCommercial, or CC-BY-NC) provided the original author and source are credited.

\section{INTRODUCTION}

Pulse Width Modulation (P.W.M) is a form of modulation using a signal to modulate the width of pulses. The power amplifier for instance is switched according to the level of the modulating signal, passing current only when the output resistance is low. The width or duration of each pulse is proportional to the amplitude of the modulating signal at that instant. The system operates with a very high depth of modulation so that overall power efficiencies of about $70 \%$ can be achieved [1].

In P.W.M, the source voltage, $\mathrm{V}_{\mathrm{s}}$ is placed across the load for a certain interval followed by shorting the load for the subsequent interval. P.W.M is a method of varying the mark-to-space ratio of the output voltage waveform during a cycle so as to minimize the magnitude of harmonics in the output [2]. PWM are of two types: (i) equal pulse width modulation and (ii) sinusoidal pulse width modulation.

\section{Equal Pulse Width Modulation}

In the modulation circuit, we have a voltage source $\mathrm{V}_{\mathrm{s}}$, a pair of self-commutating switches $\mathrm{T}_{1}, \mathrm{~T}_{3}$, a pair of line commutating switches $\mathrm{T}_{2}, \mathrm{~T}_{4}$ and an applied load [4]. Figure-1 is a single-phase P.W.M rectifier circuit while (b) is its voltage and current waveforms.

Figure- 2 consists of the voltage waveforms $\mathrm{V}_{\mathrm{s}}$; the thyristor gate pulses $\mathrm{ig}_{2}$ and $\mathrm{ig}_{4}$ for the line commutated switches. Just below this is the $\mathrm{dc}$ reference signal $\mathrm{V}_{\mathrm{r}}$ of variable magnitude while the triangular shapes are the triangular or carrier signal waves of fixed amplitude. Modulation is obtained by comparing the two signals in a comparator. The pulse width is changed by varying the magnitude of the $\mathrm{dc}$ reference signal. The dc reference signal also sets the output frequency, $\mathrm{f}_{0}$ while the carrier or the triangular signal waves determine the pulse number $\mathrm{P}$. While $\mathrm{v}_{0}$ represent the output voltage waveform, $i_{\mathrm{s}}$ represent the source current [4]. 


\section{Attributes of Multi-pulse or Equal P.W.M [4]}

- Several equidistant pulses per cycle are used.

- Equal P.W.M is so-called because all the pulses have the same width for a given value of modulation index $(\mathrm{m})$.
- Here, using several pulses in each half cycle of the output voltage can reduce the harmonic content.

- The method is a natural extension of the single pulse modulation and permits a reduction of harmonic content at low output voltages.

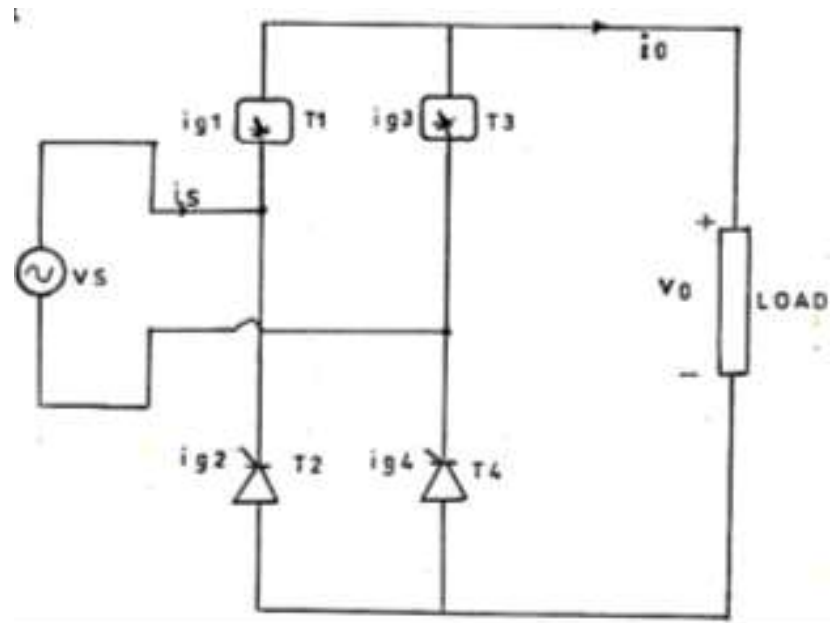

Fig-1: Single-phase pulse width modulated fully controlled rectifier circuit

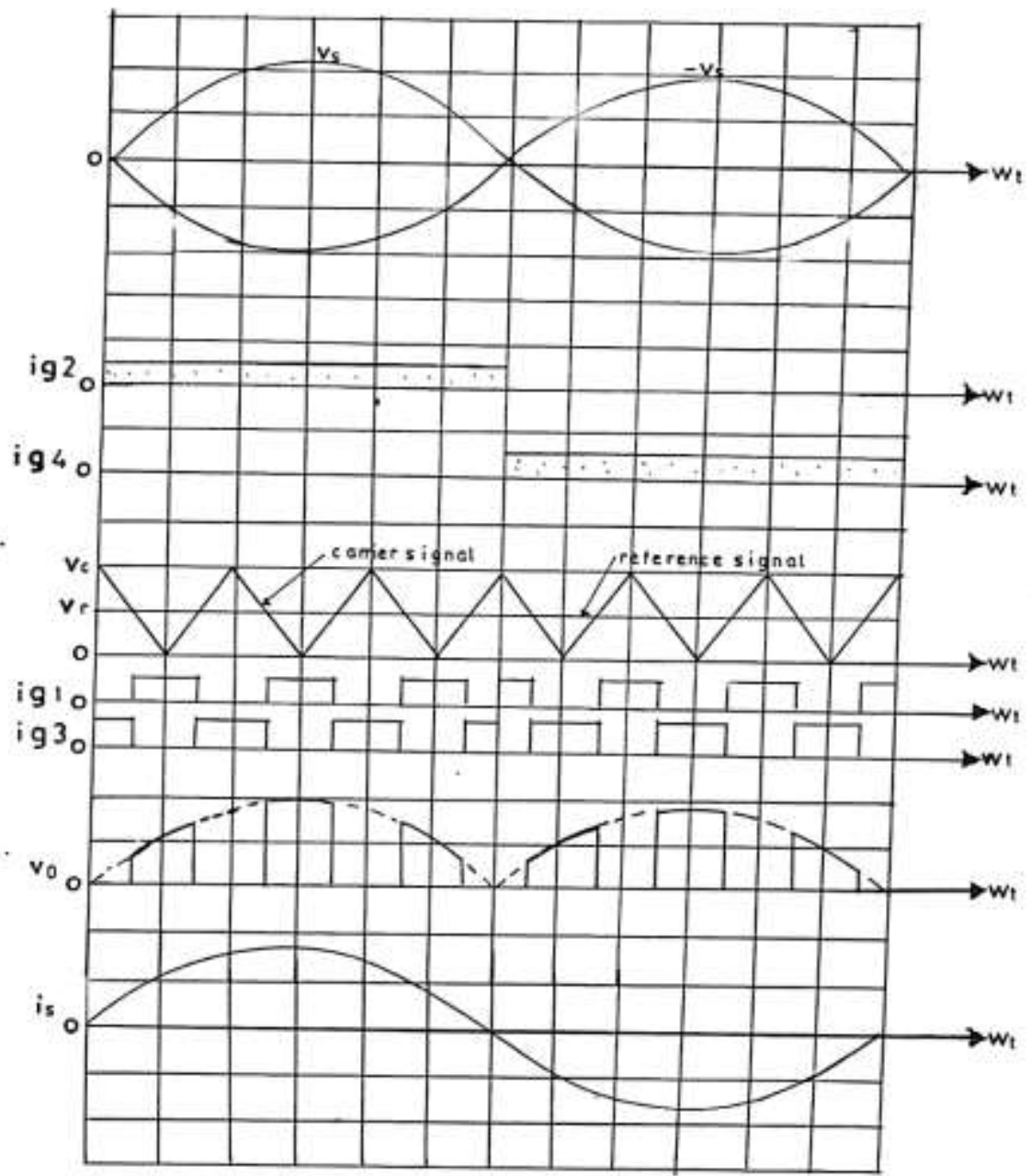

Fig-2: Its waveforms for rectification mode $\left(f_{c}=6 f_{s}\right)$ 


\section{Sinusoidal Pulse Width Modulation}

Similarly, for $V_{r}$ in equal pulse width modulation, $\mathrm{V}_{\mathrm{R}}$ can be a sinusoid in which case is called sinusoidal pulse width modulation. The method is so-called because the pulse width is a sinusoidal function of its angular position in the cycle. It is also called triangulation or P.W.M with natural sampling [4]. With $V_{R}$ as rectified sinusoid, the graphs are repeated for $f_{c}=6 f_{s}$. Figure-3 is the waveform for rectification mode of a single-phase sinusoidal P.W.M rectifier with $f c=6 f_{s}$; where $f_{c}$ and $f_{s}$ are the carrier and source frequencies respectively. The figure shows that in sinusoidal P.W.M, the d.c modulating signal in equal P.W.M described in Figure-2 is replaced by a sinusoid in which case is called sinusoidal P.W.M [4].

The rectified sinusoid $V_{R}$ is synchronized with source voltage $\mathrm{V}_{\mathrm{s}}$ and has a variable amplitude $\mathrm{V}_{\mathrm{rm}}$. The carrier wave $\mathrm{V}_{\mathrm{c}}$ also synchronized with a.c source voltage $\mathrm{V}_{\mathrm{s}}$, producing integer number of cycles in half cycle of $V_{s}$ e.g. $f_{c}=6 f_{s}$.

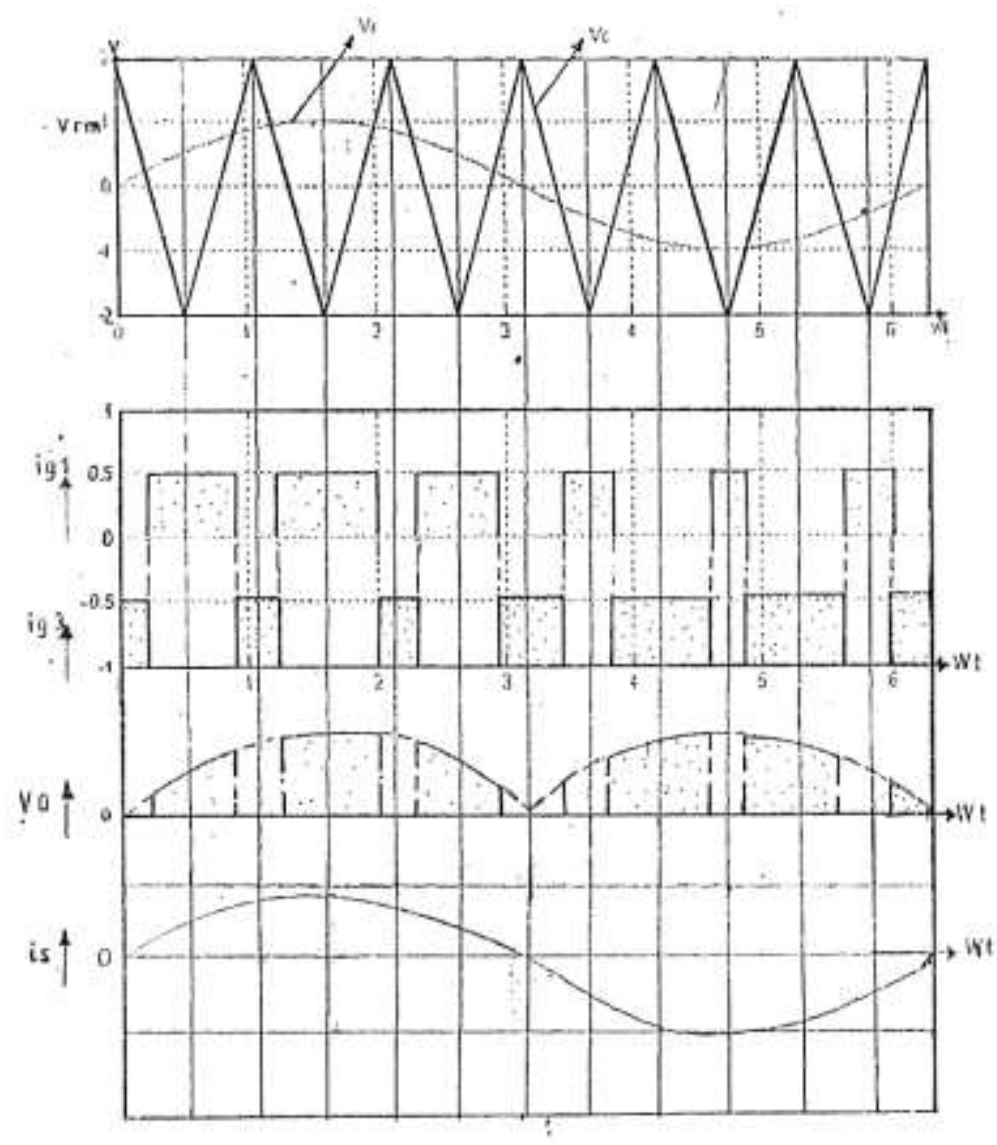

Fig-3: Waveforms for rectification mode of a single-phase bridge rectifier (sinusoidal P.W.M) $f_{c}=6 f_{s}$.

\section{Attributes of Sinusoidal P.W.M [4]}

- The d.c reference signal (in equal P.W.M) is replaced by a sinusoid in which case, is called sinusoidal P.W.M.

- Sinusoidal P.W.M is so-called because the pulse width is a sinusoidal function of its angular position in a cycle.

- The method is also called triangulation or P.W.M with natural sampling.

\section{Analysis and Power Factor Models} Single-phase Full Bridge, Voltage P.W.M Analysis [3]

The modulation index $\mathrm{m}$ is

$$
\mathrm{m}=\frac{\mathrm{v}_{\mathrm{rm}}}{\mathrm{v}_{\mathrm{cm}}}
$$

Where,

$$
\begin{aligned}
& V_{r m} \text { is amplitude of } V_{r} \\
& V_{c m} \text { is amplitude of } V_{c}
\end{aligned}
$$

For under modulation $0 \leq \mathrm{m} \leq 1$ With reference to Figure-1 [3]. If $\mathrm{T}_{1}$ and $\mathrm{T}_{2}$ are on, $i_{\mathrm{s}}=i_{0}$

If $\mathrm{T}_{3}$ and $\mathrm{T}_{4}$ are on, $i_{\mathrm{s}}=-i_{0}$

If $\mathrm{T}_{1}$ and $\mathrm{T}_{4}$ or $\mathrm{T}_{3}$ and $\mathrm{T}_{2}$ are on,

$$
i_{s}=0
$$




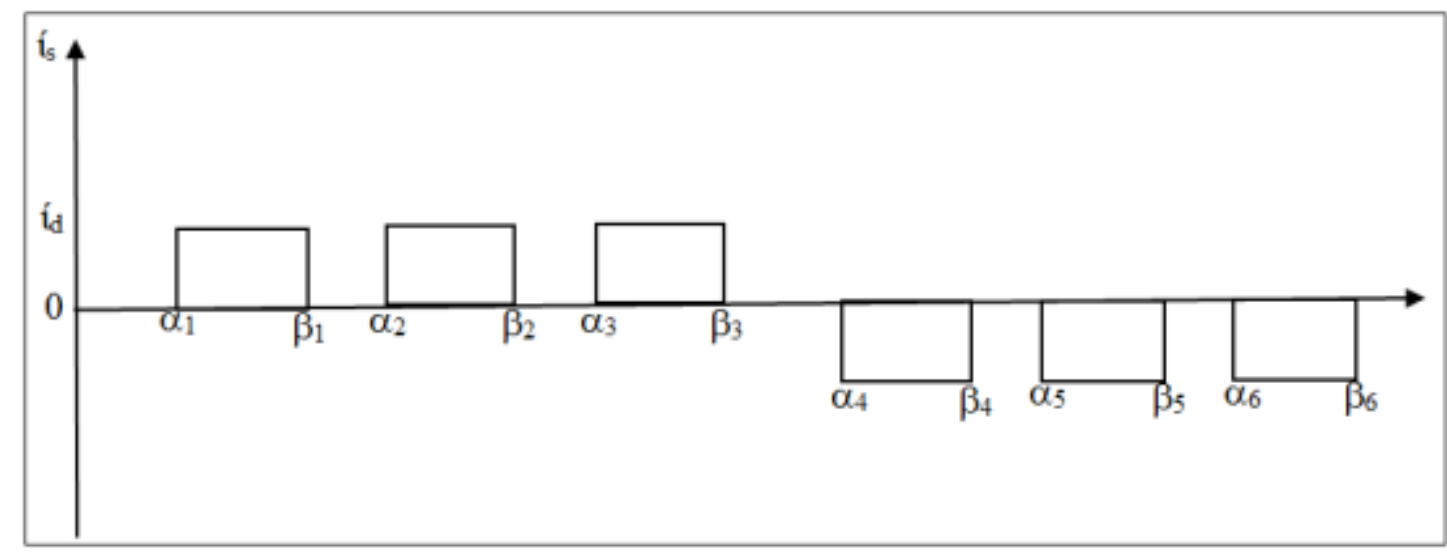

$\left\{\begin{array}{l}\alpha_{4}=2 \pi-\beta_{3} \beta_{4}=2 \pi-\alpha_{3} \\ \alpha_{5}=2 \pi-\beta_{2} \beta_{5}=2 \pi-\alpha_{2} \\ \alpha_{6}=2 \pi-\beta_{1} \beta_{6}=2 \pi-\alpha_{1}\end{array}\right\}$.

Slope for the negative slope section of the triangular wave looking at Figure-2 [3] is given as:

$$
-\frac{V_{c m}}{\pi / N_{p}}=-\frac{N_{p} V_{c m}}{\pi}
$$

Where,

$\mathrm{V}_{\mathrm{cm}}=$ amplitude of the carrier wave

$\pi / \mathrm{N}_{\mathrm{p}}=$ angular space occupied by half of the carrier signal

$\mathrm{N}_{\mathrm{p}}=$ pulse number

Its intercept at the $y$-axis is obtained as follows:

$$
\left.\begin{array}{l}
1^{\text {th }} \text { negative sloped section, y intercept }=V_{\mathrm{cm}} \\
2^{\text {nd }} \text { negative sloped section, y intercept }=3 \mathrm{~V}_{\mathrm{cm}} \\
3^{\text {td }} \text { negative sloped section, y intercept }=5 \mathrm{~V}_{\mathrm{cm}} \\
\text { kth intercept }=(2 \mathrm{k}-1) \mathrm{V}_{\mathrm{cm}}
\end{array}\right\}
$$

Hence, equation of the first negative sloped side of the carrier wave [3]

$$
\begin{aligned}
\mathrm{Y}_{1-} & =-\frac{\mathrm{V}_{\mathrm{cm}}}{\pi / \mathrm{N}_{\mathrm{p}}} \mathrm{X}+\mathrm{V}_{\mathrm{cm}} \\
\Rightarrow \quad \mathrm{Y}_{1-} & =-\frac{\mathrm{N}_{\mathrm{p}} \mathrm{v}_{\mathrm{cm}}}{\pi} \mathrm{X}+\mathrm{V}_{\mathrm{cm}}
\end{aligned}
$$

For the second, $Y_{2-}=-\frac{\mathrm{N}_{\mathrm{p}} \mathrm{v}_{\mathrm{cm}}^{\pi}}{\pi} \mathrm{X}+3 \mathrm{~V}_{\mathrm{cm}}$

For the third, $Y_{3-}=-\frac{N_{p} V_{c m}}{\pi} X+5 V_{c m}$

For the kth, $\quad Y_{k-}=-\frac{N_{p} v_{c m}}{\pi} X+(2 k-1) V_{c m}$

Similarly, for the equations of positive sloped side of the carrier waves, we have [3]:

$$
\mathrm{Y}_{1+}=\frac{\mathrm{N}_{\mathrm{p}} \mathrm{v}_{\mathrm{cm}}}{\pi} \mathrm{X}-\mathrm{V}_{\mathrm{cm}}
$$

For the second, $Y_{2+}=\frac{N_{p} V_{c m}}{\pi} X-3 V_{c m}$

For the third, $Y_{3+}=\frac{\mathrm{N}_{\mathrm{p}} \mathrm{v}_{\mathrm{cm}}}{\pi} X-5 \mathrm{~V}_{\mathrm{cm}}$

For the kth, $Y_{k+}=\frac{N_{p p} V_{c m}}{\pi} X-(2 k-1) V_{c m}$

Therefore, we have for positive and negative kth sloped section of the carrier wave:

$\mathrm{Y}_{\mathrm{K}-}=-\frac{\mathrm{N}_{\mathrm{p}} \mathrm{V}_{\mathrm{cm}}}{\pi} \mathrm{X}+(2 \mathrm{k}-1) \mathrm{V}_{\mathrm{cm}}$

$(1 \leq \mathrm{k} \leq 3)$

$$
\begin{aligned}
& \mathrm{Y}_{\mathrm{K}+}=\frac{\mathrm{N}_{\mathrm{p}} \mathrm{V}_{\mathrm{cm}}}{\pi} \mathrm{X}-(2 \mathrm{k}-1) \mathrm{V}_{\mathrm{cm}} \\
& (1 \leq \mathrm{K} \leq 3)
\end{aligned}
$$


Since these equations cut the d.c reference axis $\left(\mathrm{V}_{\mathrm{rm}}\right)$ at $\alpha_{\mathrm{k}}$ and $\beta_{\mathrm{k}}$ we have:

$$
\begin{aligned}
& \mathrm{V}_{\mathrm{rm}}=-\frac{\mathrm{N}_{\mathrm{p}} \mathrm{V}_{\mathrm{cm}}}{\pi} \alpha_{k}+(2 \mathrm{k}-1) \mathrm{V}_{\mathrm{cm}} \\
& \frac{\mathrm{V}_{\mathrm{rm}}}{\mathrm{V}_{\mathrm{cm}}}=-\frac{\mathrm{N}_{\mathrm{p}}}{\pi} \alpha_{k}+2 \mathrm{k}-1 \ldots \ldots \ldots \ldots
\end{aligned}
$$

Where

$$
\begin{aligned}
& \frac{\mathrm{v}_{\mathrm{rm}}}{\mathrm{V}_{\mathrm{cm}}}=\text { modulation index }(\mathrm{m}) \\
& \therefore \mathrm{m}=-\frac{\mathrm{N}_{\mathrm{p}}}{\pi} \alpha_{k}+2 \mathrm{k}-1 \\
& \mathrm{~m}+\frac{\mathrm{N}_{\mathrm{p}}}{\pi} \alpha_{k}-2 \mathrm{k}+1=0 \\
& \frac{\mathrm{N}_{\mathrm{p}}}{\pi} \alpha_{k}=2 \mathrm{k}-1-\mathrm{m} \\
& \therefore \alpha_{k}=\frac{\pi}{\mathrm{N}_{\mathrm{p}}}[2 \mathrm{k}-1-\mathrm{m}][3]
\end{aligned}
$$

Similarly, for $\mathrm{Y}_{\mathrm{k}+}$

$$
\beta_{k}=\frac{\pi}{\mathrm{N}_{\mathrm{p}}}[2 \mathrm{k}-1+\mathrm{m}][3]
$$

\section{Power Factor Model for Single-phase Voltage P.W.M}

For pair of pulse duration $\left(\alpha_{k}, \beta_{k}\right)$ and $\left(2 \pi-\beta_{k}\right),\left(2 \pi-\alpha_{k}\right)$, the harmonic current, $i_{n}$ is: $i_{\mathrm{n}}=\mathrm{a}_{\mathrm{kn}} \cos \mathrm{n} \omega \mathrm{t}+\mathrm{b}_{\mathrm{kn}} \sin \mathrm{n} \omega \mathrm{t}$ (using Fourier series)

Where

$$
\begin{aligned}
& \mathrm{a}_{\mathrm{kn}}=\left(\frac{1}{\pi}\right) \int_{0}^{2 \pi}\left[i^{\prime} \mathrm{kn} \cos \mathrm{n} \omega \mathrm{t}\right] \mathrm{d} \omega \mathrm{t} \\
& \mathrm{a}_{\mathrm{kn}}=\left(\frac{1}{\pi}\right)\left\{\int_{\alpha_{\mathrm{k}}}^{\beta_{\mathrm{k}}}[\text { id } \cos \mathrm{n} \omega \mathrm{t}]-\int_{2 \pi-\beta_{\mathrm{k}}}^{2 \pi-\alpha_{\mathrm{k}}}[\text { id } \cos \mathrm{n} \omega \mathrm{t}]\right\} \mathrm{d} \omega \mathrm{t} \\
& \therefore \quad \mathrm{a}_{\mathrm{kn}}=0 \\
& \mathrm{~b}_{\mathrm{kn}}=\left(\frac{1}{\pi}\right) \int_{0}^{2 \pi}[\hat{\mathrm{k} k n} \sin \mathrm{n} \omega \mathrm{t}] \mathrm{d} \omega \mathrm{t} \\
& \mathrm{b}_{\mathrm{kn}}=\left(\frac{1}{\pi}\right)\left\{\int_{\alpha_{\mathrm{k}}}^{\beta_{\mathrm{k}}}[\text { id } \sin \mathrm{n} \omega \mathrm{t}]-\int_{2 \pi-\beta_{\mathrm{k}}}^{2 \pi-\alpha_{\mathrm{k}}}[\text { íd } \sin \mathrm{n} \omega \mathrm{t}]\right\} \mathrm{d} \omega \mathrm{t} \\
& \mathrm{b}_{\mathrm{kn}}=\frac{2 \text { íd }}{\mathrm{n} \pi}\left\{\cos n \alpha_{\mathrm{k}}-\cos n \beta_{\mathrm{k}}\right\} \\
& i_{\mathrm{kn}}=\mathrm{b}_{\mathrm{kn}} \sin \mathrm{n} \omega \mathrm{t}=\frac{2 \mathrm{id}}{\mathrm{n} \pi}\left\{\cos n \alpha_{\mathrm{k}}-\operatorname{cosn} \beta_{\mathrm{k}}\right\} \sin \mathrm{n} \omega \mathrm{t} \\
& i_{\mathrm{sn}}=\sum \mathfrak{i}_{\mathrm{kn}} \Rightarrow \Sigma \frac{2 \mathrm{i} d}{\mathrm{n} \pi}\left\{\cos n \alpha_{\mathrm{k}}-\operatorname{cosn} \beta_{\mathrm{k}}\right\} \sin \mathrm{n} \omega \mathrm{t} \\
& \mathfrak{i}_{\mathrm{s} 1}=\frac{\mathrm{b}_{\mathrm{kI}}}{\sqrt{2}} \Rightarrow \Sigma \frac{\sqrt{2} \mathrm{id}}{\pi}\left\{\cos \alpha_{\mathrm{k}}-\cos \beta_{\mathrm{k}}\right\} \\
& i_{\mathrm{sR}}=\left[\sum_{\mathrm{n}=1}^{\infty} \text { ísn }^{2}\right] \text { and } \text { ís }=\left[\sum_{\mathrm{n}=1}^{\infty} \text { ísn }^{2}\right]^{1 / 2} \\
& =\left\{\sum_{\mathrm{n}=1}^{\infty}\left[\sum \frac{2 \mathrm{id}}{\sqrt{2} \mathrm{n} \pi}\left\{\cos n \alpha_{\mathrm{k}}-\cos n \beta_{\mathrm{k}}\right\}\right]^{2}\right\} \\
& \therefore i_{s}=\left\{\sum_{n=1}^{\infty}\left[\Sigma \frac{\sqrt{2} i d}{n \pi}\left\{\cos n \alpha_{k}-\operatorname{cosn} \beta_{k}\right\}\right]^{2}\right\}^{1 / 2} \\
& \text { P.F. }=\frac{i_{s I}}{i_{s}} \cos \emptyset_{1}[3]
\end{aligned}
$$




$$
\therefore \text { P.F. }=\frac{\sum\left(\cos \alpha_{\mathrm{k}}-\cos \beta_{\mathrm{k}}\right)}{\left\{\sum_{\mathrm{n}=1}^{\infty}\left[\sum_{\mathrm{k}=1}^{\mathrm{Np} / 2} \frac{1}{\mathrm{n}}\left(\cos n \alpha_{\mathrm{k}}-\cos n \beta_{\mathrm{k}}\right]^{2}\right\}^{1 / 2}\right.}
$$

Where P.F. $=$ power factor, $\mathrm{Np}=$ pulse number, $\alpha_{\mathrm{k}}$ and $\beta_{\mathrm{k}}=$ where equation cut d.c reference axis.

Note that $\emptyset_{1}=0$ since cosine component of the harmonic amplitude is zero.

\section{Three-phase Six-pulse Voltage P.W.M Analysis and Power Factor Models [3]} up with [3]:

Similarly, the three-phase six-pulse voltage P.W.M analysis and power factor models were carried out and came

$$
\text { P.F. }=\frac{\sum_{\mathrm{k}=1}^{2}\left(\cos \alpha_{\mathrm{k}}-\cos \beta_{\mathrm{k}}\right)+\cos \alpha_{\mathrm{k}}}{\left\{\sum_{\mathrm{n}=1}^{\infty}\left\{\frac{1}{\mathrm{n}}\left[\sum_{\mathrm{k}=1}^{2}\left(\cos n \alpha_{\mathrm{k}}-\cos n \beta_{\mathrm{k}}\right)+\cos n \alpha_{\mathrm{k}}\right]\right\}^{1 / 2}\right.}
$$

Where P.F. = Power Factor

$$
\begin{aligned}
& \alpha_{\mathrm{k}}=\alpha_{0}-\frac{\mathrm{msin} \alpha_{0}+(12 / \pi) \alpha_{0}+(4 \mathrm{k}-2)}{\mathrm{m} \cos \alpha_{0}+12 / \pi} \\
& \beta_{\mathrm{k}}=\beta_{0}-\frac{\mathrm{m} \sin \beta_{0}-(12 / \pi) \beta_{0}+4(\mathrm{k}-1)}{\mathrm{m} \cos \beta_{0}-12 / \pi} \\
& \alpha_{0}=\beta_{0}=\text { rough values of alpha and beta obtained graphically } \\
& \mathrm{m}=\text { modulation index, range }=\mathrm{m}(0 \leq \mathrm{m} \leq 1) \\
& \mathrm{k}=\text { variable with range, } \mathrm{k}(1 \leq \mathrm{k} \leq 3) \\
& \mathrm{n}=\text { harmonic order, range } \mathrm{n}=1,3,5 \ldots \infty
\end{aligned}
$$

\section{SIMULATION/RESULTS}

With the power factor expressions obtained in equations 3.26 and 3.27, Matlab [7] was employed in programming and simulation of the single-phase and three-phase voltage P.W.M converters and the resulting curves are displayed in Figures 4 \& 5 respectively.

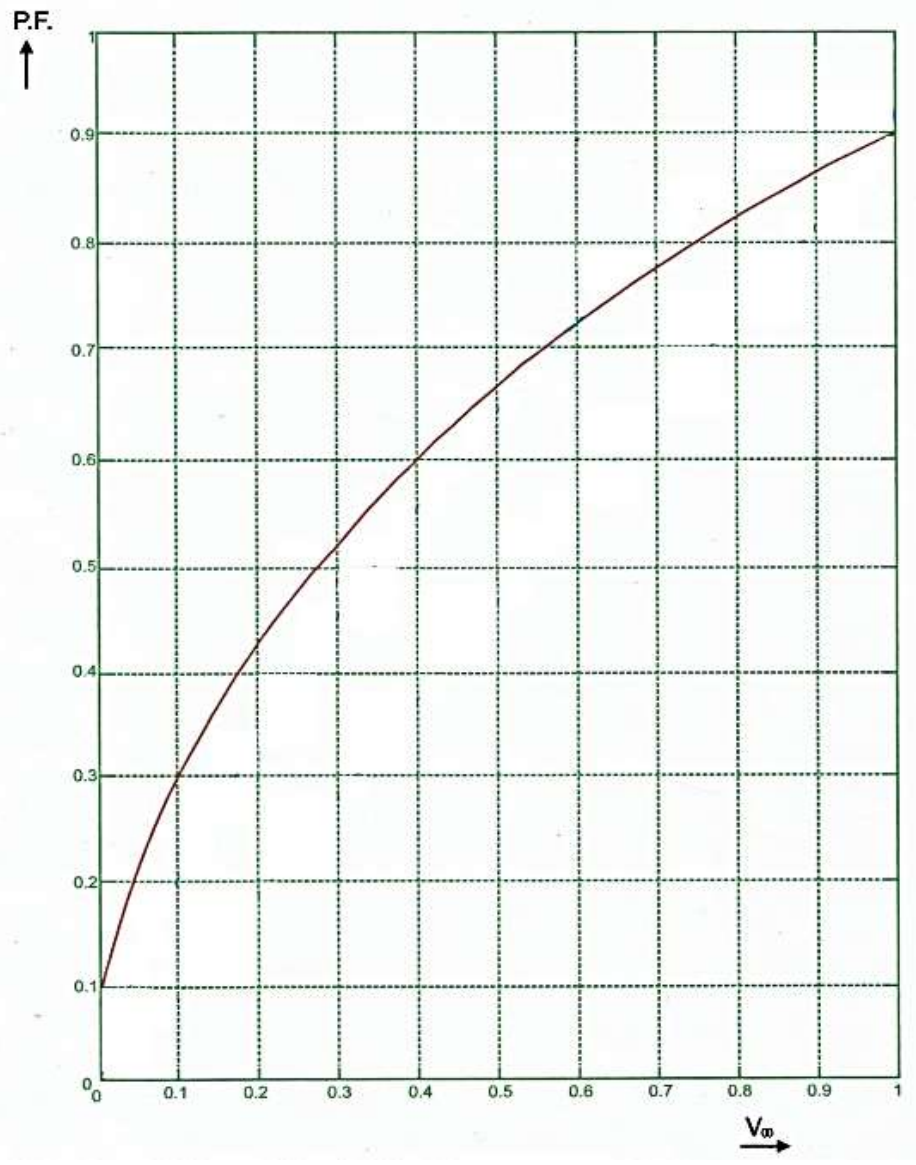

Fig-4: Plot of single-phase full-bridge P.W.M converter 


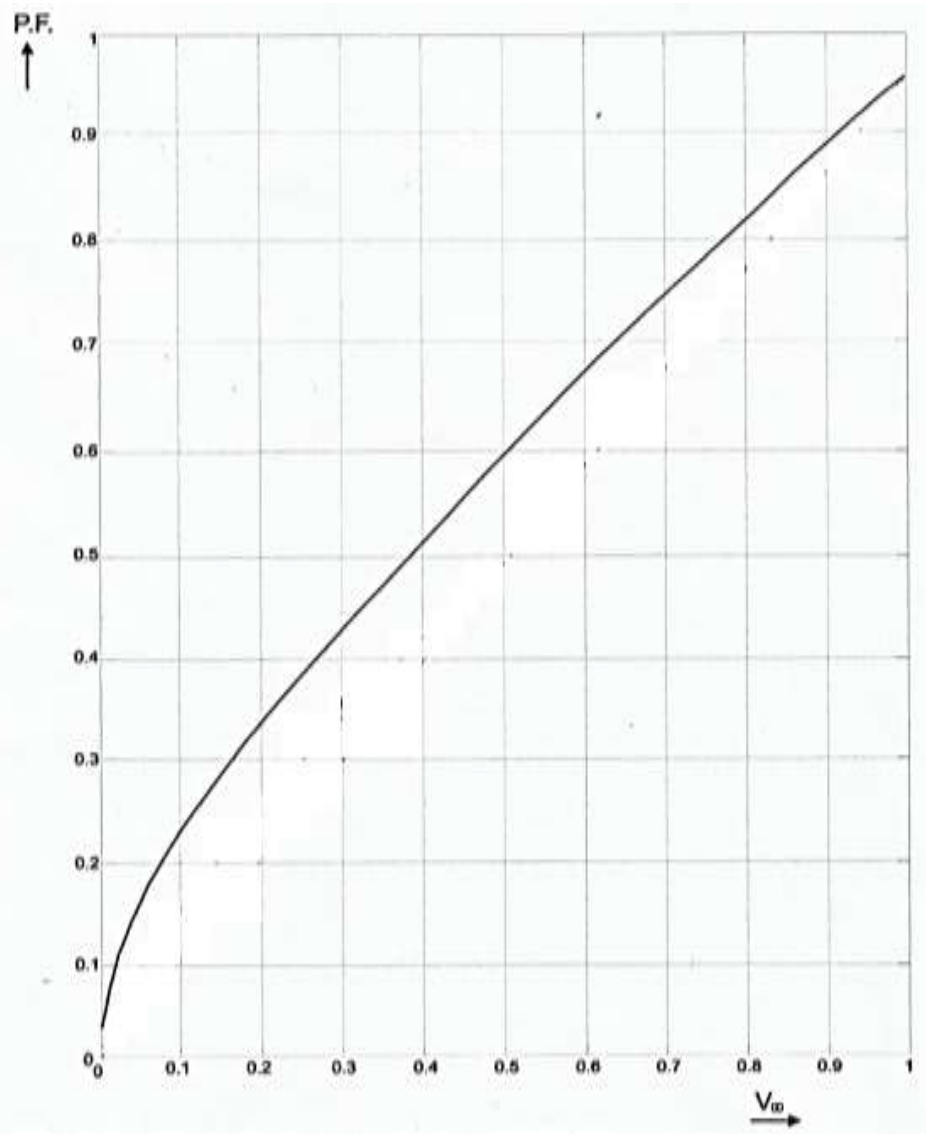

Fig-5: Plot of three-phase full-bridge P.W.M converter

\section{ANALYSIS RESULTS}

P.W.M in single or three-phase system is a premier when compared with other phase-controlled methods. It is better at low output voltage demand. Again, by using several pulses in each half cycle of the output voltage, it can reduce harmonic contents at low output voltages. Moreover, in P.W.M, control is made independent of alpha $(\alpha)$ or firing angle of the thyristor and so all the switching loss problems and electromagnetic interference (EMI) noise associated with switches/ switching are totally eliminated. Although P.W.M has all these qualities, the a.c input power factor still degenerate with decrease in the load voltage. Therefore, both P.W.M and other phase control methods are tolerable where nonlinear load concentration is low.

\section{CONCLUSION}

Since harmonics decrease with the increase in rectifier pulse numbers, the three-phase six-pulse rectifiers have lower amplitude of harmonics than the single-phase two-pulse rectifiers and therefore have better power factors. Again, P.W.M is better at low output voltage demand and by using several pulses in each half cycle of the output voltage it can reduce harmonic contents at low output voltages. Although all these good qualities are abound in P.W.M the ac input power factor still degenerate with decrease in load voltage and therefore P.W.M and other phase control methods are tolerable where nonlinear load concentration is low.

\section{REFERENCES}

1. Collins. Dictionary of electronics (Definitions for Digital Age). Davidson Pre-press Graphics Limited, Glasgow. 2004.

2. Dubey GK. Power semiconductor-controlled drive, Prentice Hall International Edition. 1989.

3. Ibekwe BE. Comparative study of converter power factor correction techniques. Masters Dissertation, Enugu State University of Science and Technology (ESUT), Enugu. 2010; 70-76.

4. Ibekwe BE, Eneh II, Ude IJ. Guiding Principles in Selecting AC to DC Converters for Power Factor Correction in AC Transmission system. IJERA Journal. 2014 Oct;4(10).

5. Ogbuefi UC. A power flow analysis of Nigerian power system with compensation on some buses. Ph.D Thesis, University of Nigeria, Nsukka. 2013.

6. Vanguard Newspaper. Power situation of Nigeria. 2016; (pp.12).

7. Okoro OI. Introduction to Matlab/Simulink for Engineers and Scientists. John Jacob's Classic Publishers Limited, Enugu. 2005. 